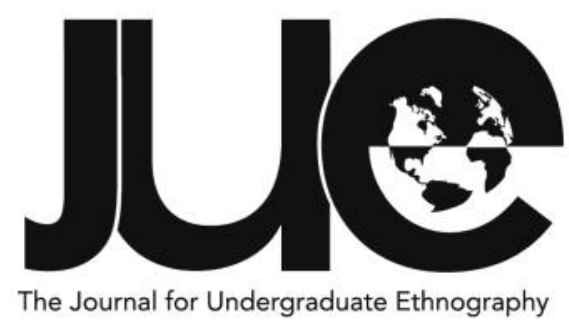

\title{
Beyond Invisibility: A REDress Collaboration to Raise Awareness of the Crisis of Missing and Murdered Aboriginal Women \\ Natalie Marie Lesco
}

St. Francis Xavier University, lesconatalie@gmail.com

\section{ABSTRACT}

This article describes the impact of a case study of the REDress project on a university campus in Nova Scotia, Canada. The REDress project is a grassroots initiative that operates at the local level to empower Aboriginal women through an evocative art exhibit: the hanging of empty red dresses symbolizing missing and murdered Indigenous women and girls and the emptiness of the societal response to the violence committed against them. Using a participatory-action research model (PAR), which guides the exploration of the kinds of ideas instilled within this community-based initiative, my research demonstrates the potential this project has to mobilize local Indigenous women's perspectives and voices, in order to break the silence to which they are often subjected through structures of oppression. This process relies on the establishment of meaningful connections with members of the StFX Aboriginal Student's Society and creating a transparent research process, while also encouraging action in the form of awareness building. The project makes a political statement that resists the ascribed invisibility of Aboriginal women by honouring the lives of missing and murdered Aboriginal women. As a community-based initiative, the REDress project demonstrates the beginnings of reconciliation by cultivating meaningful relationships that provide hope for the future. 
$\mathrm{M}$ issing and murdered. These are two words that describe the multidimensional condition of violence that Aboriginal women experience as a consequence of ongoing processes of colonialism. Approximately 1,181 Aboriginal women have been reported as either missing or murdered between 1980 and 2012, and are "three times more likely than non-Aboriginal women to be killed by a stranger" (NWAC 2015; RCMP 2014). Aboriginal women represent 16\% of all female homicides that have occurred in Canada while making up only $4 \%$ of the national population (RCMP 2014). This disproportionate relationship is a consequence of the dehumanizing colonial processes of the Canadian state that have been occurring for decades.

To be human, and yet socially constructed as less than human, is a contradiction that has shaped much of what Aboriginal women recognize as their identity within the confines of the Canadian state. This dehumanization, in which women are framed as object rather than subject, is a reality that plagues many Aboriginal women throughout the country (Archuleta 2006). There is a long history of colonization in Canada, and its detrimental effects are still visible within our society today. The explicit attempt to strip Indigenous women of their identity and destroy Aboriginal cultures in order for assimilation to take place has subordinated these women to the boundaries of society. The ways in which Aboriginal women are represented in our society today contribute to the ongoing exposure to violence in their lives.

The present position, in which Aboriginal women live in marginal, racialized, gendered and vulnerable spaces, must be understood within its historical context. The displacement of Aboriginal communities and their expulsion onto reserves, coupled with the denial of Aboriginal rights and equity within the Canadian justice system, has created socioeconomic disadvantages for Aboriginal peoples. Poor infrastructure, the effects of intergenerational trauma such as violence in the family, and the breakdown of community structures on some reserves has pressured many Aboriginal people to leave their families and reserves in search of a better way to live (NWAC 2010). For women, this usually involves moving to urban areas where there are significant challenges in fighting stereotypes and finding work, making women more susceptible to forces of exploitation, such as drug use and prostitution (Oppal 2012). It is through these types of activities that Aboriginal women are framed as being at fault for their own living conditions (poverty, addictions, abuse). As a result, until recently there has been little public or policing response to the crisis of missing and murdered Aboriginal women.

Current government efforts to mitigate the effects of colonialism are ineffective, as they are drawn from preexisting policies which are extensions of colonial ideologies. This paradoxical approach will not affect existing paternalistic attitudes or actions of indifference towards Aboriginal women unless there is systemic change and reconciliation. It is from within this marginal position that Aboriginal women have been constructed as vulnerable and weak, strongly contrasting the traditional roles they previously occupied within many Aboriginal societies (RCAP 1996).

In order to reclaim their voices, Aboriginal women have come together to combat the gendered and racialized policies and systems that have rendered them invisible within the Canadian state. An example of this is the REDress project, a grassroots initiative that operates at the local level to empower Aboriginal women through an evocative art exhibit: the hanging of empty red dresses. The placement of red dresses in public spaces serves as a political statement against the invisibility of Aboriginal women and simultaneously honours the lives of those women who have gone missing or who have been murdered. As a community-based initiative, the REDress project, organized by 
both Aboriginal and non-Aboriginal students, created the space for the beginnings of reconciliation, cultivating dialogue and producing meaningful action oriented toward collective awareness campaigns.

\section{The REDress Project}

The REDress project was created by Jamie Black, a Métis artist based in Winnipeg, in attempt to bring the crisis of missing and murdered Aboriginal women to the public's attention. The initial aim of the project was to collect 600 red dresses that would not only reflect the staggeringly high rates of missing and murdered Aboriginal women, but that could also be used to create a display in the Winnipeg museum. Solo exhibitions have also been held at various universities and communities throughout Canada.

The importance of visual representation is described by Black as "an aesthetic response to the more than 1000 Missing and Murdered Aboriginal Women in Canada" in which the aim is to "draw attention to the gendered and racialized nature of violence crimes against Aboriginal women and to evoke a presence through the marking of absence" (Black 2014). It is the continual negative representations of Aboriginal women through media portrayals that Black describes as a major catalyst for the negligence towards the missing and murdered Aboriginal women crisis in Canada. For example, missing Indigenous women are often presented to the public through posters using mug shots to identify potential victims. This approach criminalizes the women, thereby restricting their public profile within boundaries that ultimately disadvantage them (Pratt 2005). By countering these destructive narratives with the use of powerful symbolism-the colour red encompassing ideas about "blood, sexual energy, and violence"-the REDress project seeks to return a sense of humanity back to the victims (Marrouat 2011).

This independent project examines the ways in which Aboriginal women are both empowered and limited through localized grassroots social movements. By participating in the organization and production of a StFX university-based REDress project (See Figure 1), I documented and analyzed how Indigenous and non-Indigenous students worked together to raise public awareness of the systemic discrimination that Indigenous women face. In doing so, I determine the narrative the REDress project offers in response to the issue.

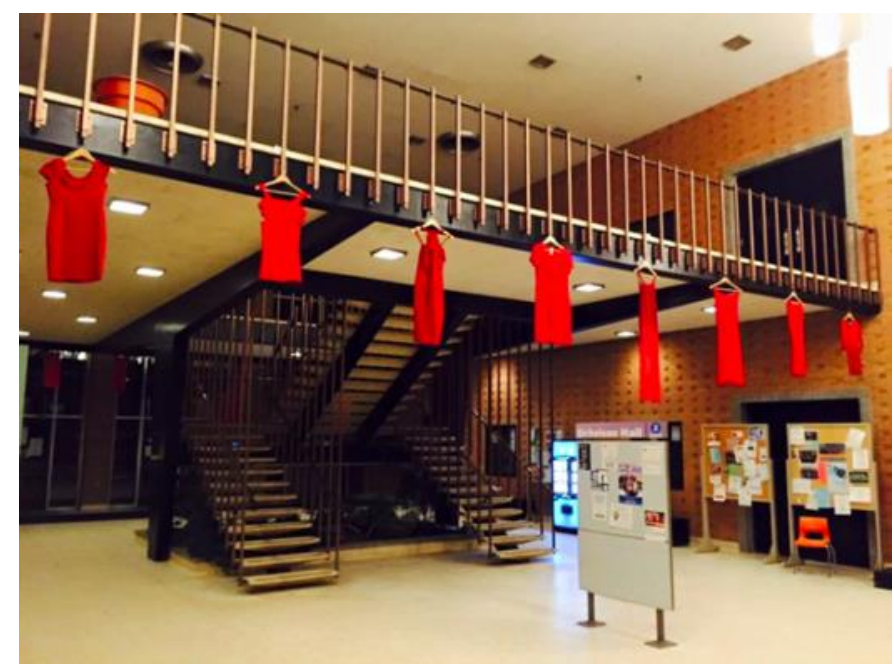

Figure 1: Dresses hanging in Nicholson Hall, 2016 (Source: Natalie Lesco)

\section{Methodology}

The principal methodology used in this study was participatory-action research (PAR), involving participant observation, ethnographic fieldwork, interviews and a focus group. Information was collected according to Geertz' (1973) concept of thick description. By compiling detailed observations, I described information as it happened as objectively as possible, uncovering underlying patterns that structure the event and the ways in which culture is symbolically expressed.

As a component of my undergraduate honours thesis research, the study and the project commenced in September 2015 and ended in May of 2016. The REDress project was presented in four different locations on the St. Francis Xavier University (StFX) campus in order to attract the attention of students from various academic backgrounds. StFX is a small university of around 4000 students, located on Mi'kmaq territory in the small rural town of Antigonish, Nova Scotia.

While the dresses were on display, I spent much time monitoring the project with the other members of the organizing committee, using our meetings and general interactions as a component of PAR. Importantly, this particular methodology involves the researcher 
creating and sustaining a critical awareness with research participants in order to attain a more decolonized way of understanding both literature and data (Smith 2012). PAR allows Indigenous ways of understanding to be implemented into the process of research. The utilization of an inclusive research design, involving the ideas of both researcher and participants, creates an informative and transparent process (Smith 2012). This process involved providing my field notes to participants for their review at each subsequent meeting and allowing participants to give feedback to guide the next steps. In addition, interviews and a focus group with the four young Indigenous women served to ascertain, more directly, the opinions of the REDress organization committee members on their experience in producing the exhibit and their thoughts of the public responses.

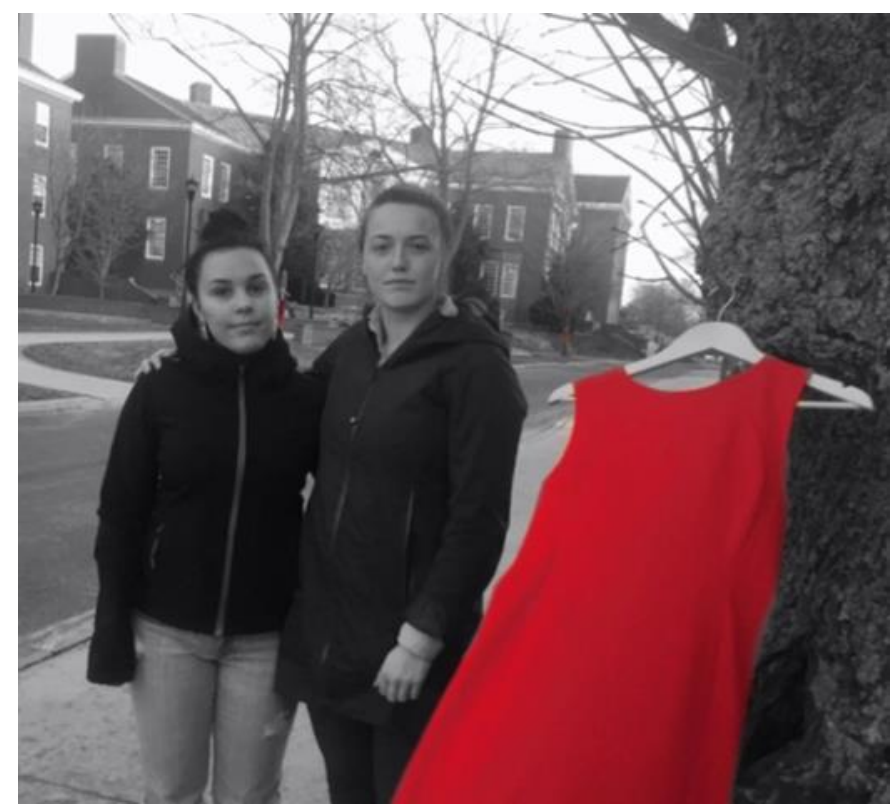

Figure 2: Morningstar (left) and myself (Source: Morningstar)

PAR begins with building relationships. Building on my existing relationships with members of the Aboriginal Student Society, I reached out to them, stating my interest in collaborating with the REDress organization committee to help bring the REDress project to StFX. This interaction led to the formalization of a committee made up of myself, a nonIndigenous woman, and four Indigenous women: Shanna, Morningstar, Miss Cremo and Jasmine (see Figure 2). The criterion for involvement in the committee was simply an interest in assisting with the production of the REDress project at StFX.
Six organizational meetings were held between January and March. These were informal meetings used to structure the project and included different combinations of members of the organizational committee, based on availability. I took detailed field notes during meetings and interviews and while the project was on display. Questions emerged regarding both the success and shortcomings of the project, as well as general issues that Indigenous women are faced with. These discussions were recorded and made up a large portion of my field notes, both of which helped me contextualize violence against Aboriginal women, while also informing the positions of the REDress organizing committee.

A focus group was held on March 5, 2016, a week after the project was first put on display. It consisted of Jasmine, Miss Cremo, and Morningstar, who had all agreed to take part in the structured and semi-structured interview process together. The questions revolved around the REDress project and participants' opinions of the impact and potential success of the exhibit. This process involved telling personal stories and experiences that reflected those which the REDress project intended to expose, and also providing critical feedback about the process as a whole. The focus group lasted about two hours in total.

Additional interview data were collected from structured interviews guided by a journalist from the Antigonish Casket newspaper who was not involved in the process of PAR. Since the interviewer asked many questions about the REDress project, I gained permission to record the process myself and use it as an additional source. This interview also involved myself, Miss Cremo, Jasmine, and Morningstar.

\section{Indigenous Feminism}

The project was analyzed through the theoretical framework of Indigenous Feminism. What many Aboriginal women find unsatisfying about feminism is the homogenization that they are subjected to when represented as a "unified front" (Monture-Angus 1995: 182). As Lee Maracle explains, "feminism is racist because it does not account for any other woman other than White females" (1995: 137). The diverse identities and experiences of 
Aboriginal women are taken into account by the Indigenous feminist perspective, combating the "double discrimination" that is a result of patrilineal narratives enforced in colonial society (Couture-Grondin and Suzak 2013: 27). The resultant social, economic, and political barriers are paramount in the perpetuation of this vicious cycle of systemic discrimination. It is through the deconstruction of current Canadian, and therefore inherently colonial, justice systems that we can come to expose the gendered forces that act to dehumanize, disempower and limit the social and economic mobilization of Aboriginal women.

Suzak (2010) envisions violence against Aboriginal women as a result of the sexualization of women through processes of colonization, upheld in the present day by legislation, such as the Indian Act of 1876, that continues to subjugate Aboriginal women into spaces of heightened vulnerability to violence. That violence is not just physical, but manifests in many different ways, continually affecting Aboriginal women. By taking into account the extent of the uniquely structural and colonial oppression that Aboriginal women face, we can better understand the complexity of such violence (Monture-Angus 1995). Indigenous feminism is therefore a combination of both post-colonial and feminist theories with a specialized focus on the experiences that differentiate Aboriginal women from white middle-class women and as such, Western feminist theory (Suzak 2010: 3).

Instead of occupying the periphery and accepting imposed definitions of womanhood, as in Western notions of feminism, Indigenous feminism offers a space in which Aboriginal women's understanding and definitions are at the forefront (Cunningham 2006). The knowledge keepers, in this case Indigenous women, have the power to create and share the factors that have influenced their lives (Cannon and Sunseri 2011: 46). Instead of conforming to established ideas of gendered forces, the intersectionality of race, class, and gender are emphasized. This gives Indigenous women the power to define themselves, an important aspect of self-determination.

A common criticism of Indigenous feminism by Aboriginal women themselves is that it does not address enough issues that are considered highly important in Indigenous communities, such as autonomy (Suzak 2010). In addition, offering a single definitive characteristic of Indigenous feminism is often difficult because of the diversity that it, as a theoretical framework, encompasses (Suzak 2010).

However, the use of Indigenous feminist perspectives largely informed the decision to use participatory-action research, as it serves as an avenue for the decolonization of understanding. Presenting the voices of Indigenous women was a fundamental element in increasing self-determination. Similar to existing Indigenous feminist literature, the aim is to expose and deconstruct the gendered and racialized forces of violence that often go unnoticed in society (Archuleta 2006: 89). Feminist theory alone cannot account for all of the experiences of women, and therefore, Indigenous feminism offers an intersectional pathway towards specialized knowledge.

\section{The Process}

\section{Breaking Barriers: REDress and the Event Review Committee (ERC)}

In order to display the REDress project on the StFX University campus, permission was needed from the Event Review Committee (ERC). The application process requires a written submission to the StFX Student's Union committee that critically evaluates the perceived risk an activity may present to the individuals involved. Initially, our first two proposals were rejected. It was suggested that we include support resources, such as fact sheets and helpline numbers in the event that the project generated an emotional response. The ERC committee also wanted us to take down the dresses at night, as a previous installation at Acadia University had been vandalized (Squires 2015). However, we felt that to take the dresses down at night would compromise the integrity of the REDress project and the ideas it represents. Our response was as follows:

To remove the dresses in fear of vandalism contradicts the reasons that it is installed in the first place. It is the nature of ignorance in Canadian society surrounding the 
unacknowledged crisis of missing and murdered Aboriginal women that the REDress exhibit is attempting to combat. Vandalism of the dresses would serve as a testament to the ongoing crisis and also indicative of the problem that still exists. It is for this reason that we do not fear potential vandalism... The outcome of this project is also important, as we must consider larger problems that such an installation is trying to raise awareness about (E-mail response to the ERC, Feb. 26, 2016).

Although the university was well intentioned in their attempts to keep campus safe, it is difficult for us to understand why the hanging of empty red dresses around campus was so hard to negotiate. Of course, it is a symbol of something deeply problematic and embedded within Canadian society, but the dresses themselves should not pose a threat. That the ERC was hesitant to expose the crisis of missing and murdered Aboriginal women in all its intricacies, and to bear the potential effects, is emblematic of the silence that has characterized Indigenous issues for decades.

The required ERC application is indicative of the larger processes affecting Aboriginal peoples within institutional settings. In their quest for self-determination and selfexpression, Aboriginal men and women alike want to have control over their lives, as do nonAboriginal peoples. However, when working within a colonial system that systemically disadvantages them, it is hard to yield productive results. As such, the actions of the ERC exemplify the regulation of information wherein there needed to be approval of the event prior to the implementation of it. The risk -assessment model used to gain approval to hang the REDress project on the grounds of the university proved to be problematic not only in the process but also in the message that it translated to the members of the REDress organization committee. The process was frustrating, as Jasmine LaBillois conveys: "I have to put in a little bit of criticism, especially towards the university and how difficult they made it for us to sort of put this up, we were rejected two times through the ERC which was just frustrating".

In response to the request of the ERC, we provided additional information on posters, such as helplines, that offered background information on the topic. It is clear that the institutional barriers demonstrate, firstly, a lack of awareness about the crisis of missing and murdered Aboriginal women in the university community. But secondly, the reply from the university, fearing the emotional responses the exhibit may evoke, delegitimized the reality that many Aboriginal communities are faced with. Jasmine stated that "I feel like a lot of our truths are not being told within these walls of StFX". Although the topic of missing and murdered Aboriginal women is sensitive in nature, it is a complex facet of social relations that needs healing, and healing begins with addressing the issue. The evocative presence of the exhibit is powerful, and the same response could not have been received if any element of the exhibit ceased to exist.

The risk-assessment process at the university should take into consideration the

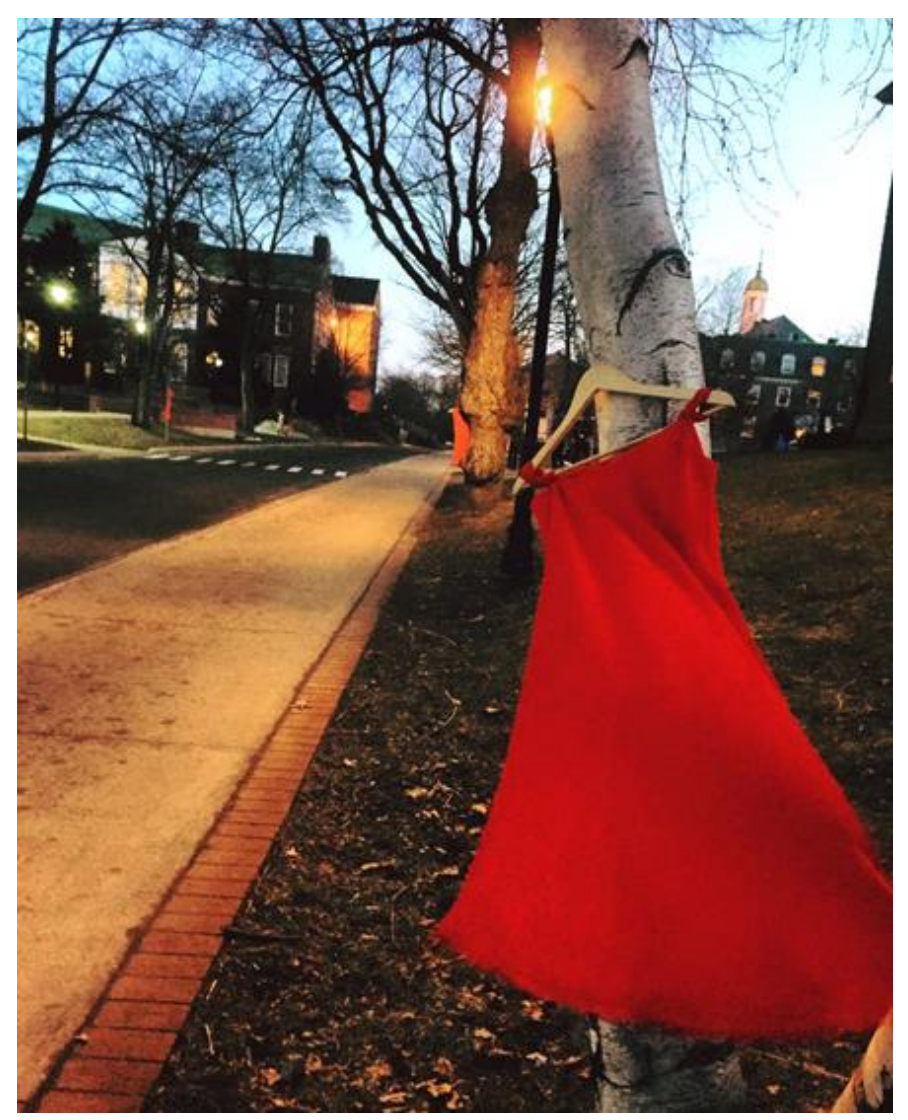

Figure 3: Dresses hanging outside Schwartz, 2016 (Source: Natalie Lesco) 
barriers it imposes on groups of people when it is attached to strong political and social issues. The arduous process of trying to prove the legitimacy of the REDress project was emotionally taxing on the organization committee. The underlying message the ERC communicated in their decision to reject the event proposal was that the issues Indigenous peoples face need to be appropriated, so as not to offend those who are unaware of the situation. The underlying assumption that the project posed a threat to the university was perceived as indirect racism and structural discrimination.

As our frustrations escalated, we consulted the members and executives of the Aboriginal Student's Society in order to create a strategy to expedite the process. There was unanimous disapproval of the way the ERC was handing the application, which we attributed to a cultural disconnect between Indigenous and nonIndigenous students. As an act of explicit resistance, we decided to go ahead and hang the dresses before gaining approval. A few hours after installing the exhibit, an administrator personally e-mailed me with permission, signing off her e-mail with "Kudos!" (See Figure 3). It is evident that for mobilization of awareness to occur there is usually a degree of resistance that may be encountered. This is an example of how allies must continue to support Indigenous people's expression and rights, if any significant action is to occur.

\section{Schwartz}

In the weeks leading up to the installation, the committee had created posters and a Facebook page asking for donations of red dresses and advertising the exhibit. Over the course of about three weeks we received over 20 donations from friends, family, professors, community members and strangers. The call for donations stimulated initial interest, as evidenced in the growing views of our Facebook page. Having collected enough dresses, Morningstar and I proceeded to install the REDress project on the morning of February 29th in front of the Gerald Schwartz School of Business (See Figure 4). Importantly, we did so without confirmed approval from the ERC.

The process involved weaving fishing line through the branches of the trees to secure the

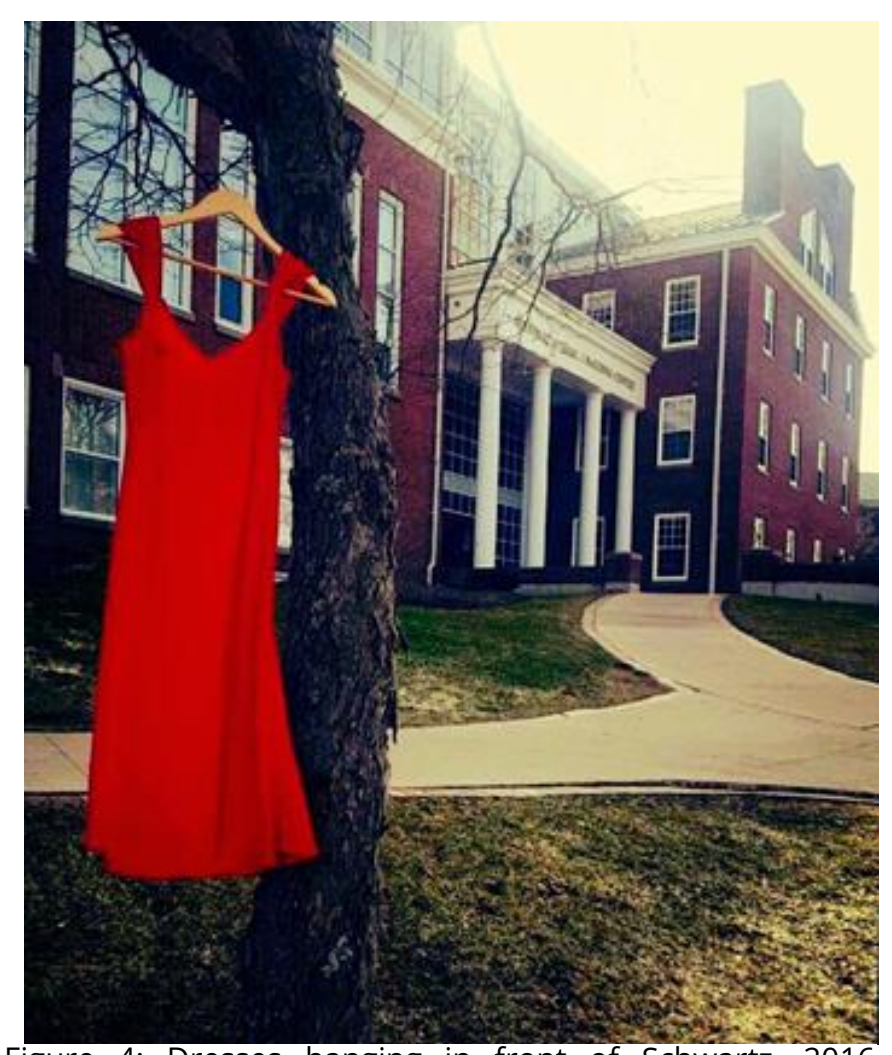

Figure 4: Dresses hanging in front of Schwartz, 2016 (Source: Natalie Lesco)

wooden hangers that the dresses rested upon. When we had evenly dispersed the dresses, there were two striking rows of red that lined the road. A very highly visible area on campus, Schwartz is located on a one-way street where there is little traffic but many pedestrian students. This is one of the most popular routes to get to campus from Main Street in Antigonish, and, as such, was chosen because the dresses would be seen by both students and community members passing by. The tall trees that line the street were also an essential piece of the project, as there needed to be space to hang the dresses evenly so they would be aesthetically appealing.

Even during the early hours of the morning, the dresses were turning heads. The few people passing by were interested in what the dresses represented and did not hesitate to ask questions. As I was reinforcing the dresses in the trees, a woman walking into Schwartz complimented the dresses. She stated that "it was about time someone around here did something" to raise awareness about the crisis of missing and murdered Aboriginal women. She took a moment to really soak in the impact of the exhibit, turned to me, and said "you know, this is powerful and this means a lot to me... my niece is one of them...she is Aboriginal, 
and she is missing". Having been unexpectedly struck by a wave of emotion, I responded with, "this is for her", as the woman turned away and continued to walk into the building. The two days that the dresses were showcased in front of Schwartz were very windy, although bright and sunny. The dresses had to be reinforced multiple times throughout the day with fishing line so that they would not blow away. However, in between the time I had left for class and then returned afterwards, the dresses were placed in different trees and in different spots than they had originally been hung. Upon inspection, it was clear that the fishing line had broken and the dresses had fallen, but people walking by took the initiative to hang them back up. Even as I was walking to hang up a dress in the afternoon after it had fallen, one student walked by and hung it up before I could get to it. This initiative suggests there was an evident importance to the exhibit which garnered respect. Though people may not have been aware of the purpose of the dresses, the arrangement, the colour, posters and overall appearance of the exhibit clearly demonstrated that they were there for a reason. This was a

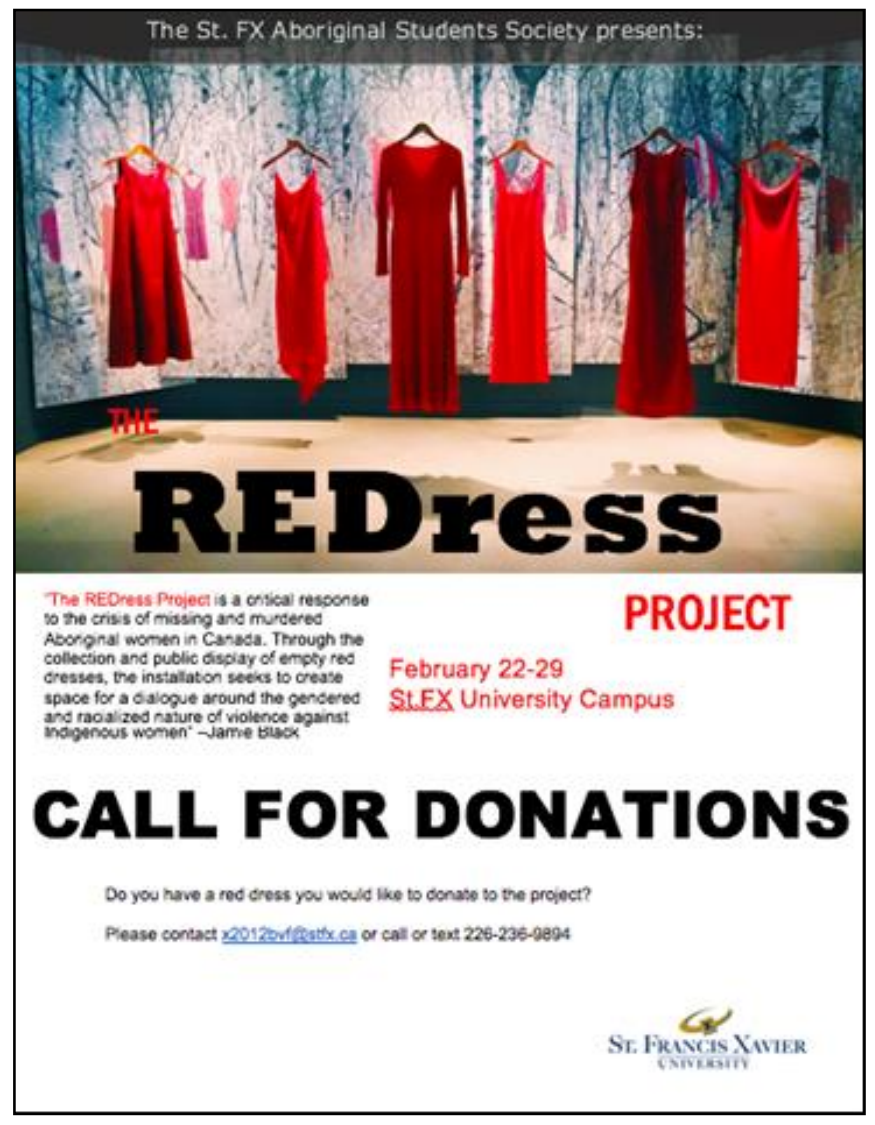

Figure 5: Poster advertising the REDress Project, 2016 (Source: Natalie Lesco) very positive form of feedback on campus and it demonstrates the engagement that the university community has with the exhibit against all the ERC's expectations. The following two weeks, the dresses were showcased in two different areas of campus, receiving the same general curiosity and interest.

\section{International Women's Week}

Given the positive reaction to the project, it was suggested to the organization committee by a faculty member that the dresses be included in the International Women's Week: Feminist Future's segment. Keynote speaker and postcolonial feminist scholar, Sherene Razack, brought the attention of the audience to the dresses hanging along the auditorium walls. She described how the empty dresses are symbolic of the way Indigenous women are reduced to body parts, ascribing and reinforcing the invisibility of Aboriginal women in the legal system. Dr. Razack discussed the case of Cindy Gladue, an Aboriginal woman who was brutally murdered in 2011. The way in which Cindy Gladue's case was handled by the court system is indicative of the way Aboriginal women have been constructed as disposable entities by the government, undeserving of legitimate protection by the state (Razack 2015: 24). This case is exemplary of the flaws inherent in a legal system that does not account for the realities of Indigenous and other marginalized peoples.

\section{Analysis}

The following section examines the evidence complied from the applied methodology, theory and process of the exhibit. The purpose of this section is to demonstrate how the REDress project functions as a reflexive, fluid and influential exhibit that is meant to engage with the environment in which it is situated.

\section{Raising Awareness and Recognizing the Problem}

The power of the exhibit is drawn from the symbolism that it uses to portray Aboriginal women. The colour red itself has multiple implications which the artist, Jamie Black, intended to convey. As Morningstar, a member of the organizational committee states, "the colour red... red represents power, and the violence and the blood and the things that 


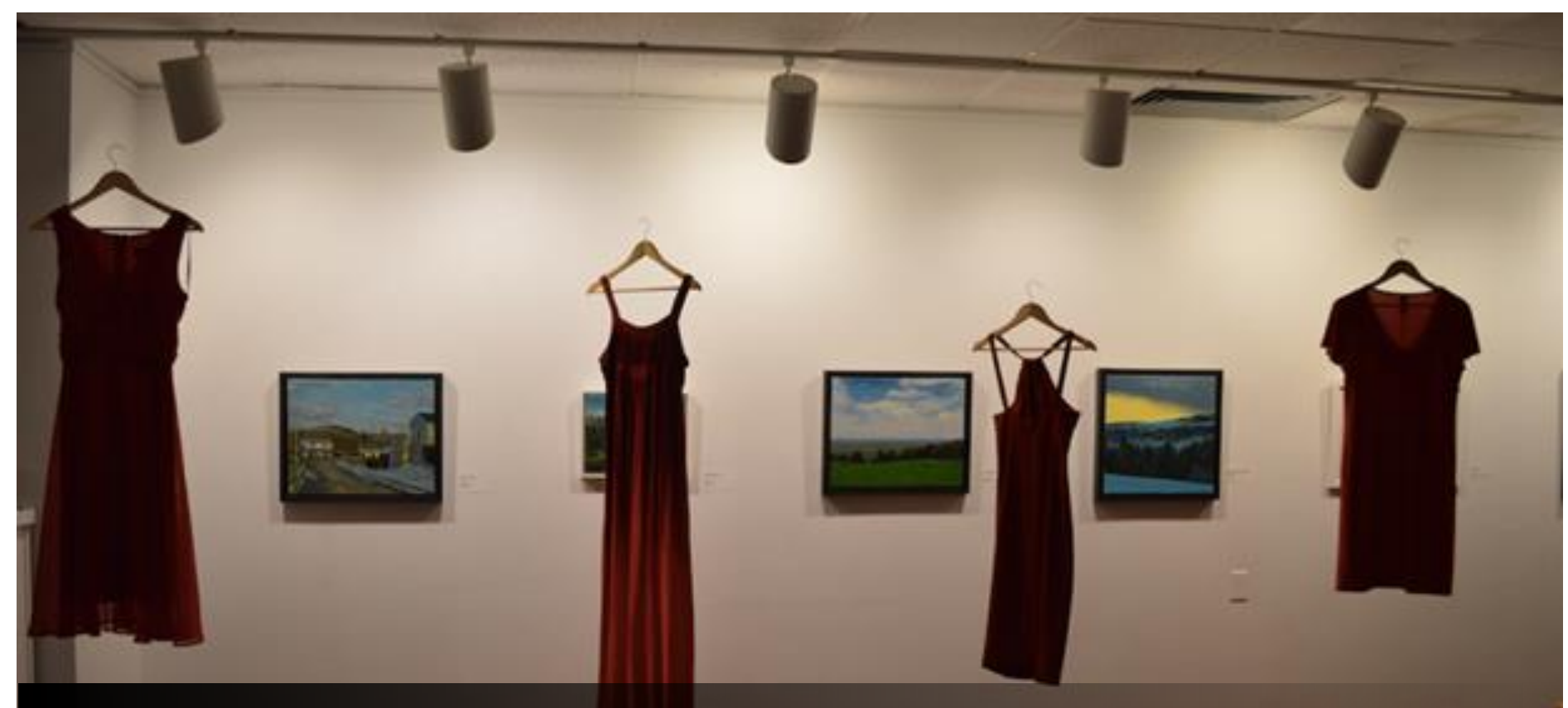

Figure 6: Dresses hanging at the Youth Activism Conference, 2016 (Source: Natalie Lesco)

these women have gone through, which is why these dresses hang where they are today". The visual aspect of the project is striking and it is meant to draw attention to the urgency and depth of the problem that Aboriginal women face. In addition to those visual elements that Morningstar describes, Black meant to imbue the dresses with a component of sexual energy.

The marked identity of Indigenous women in Canada is both recognized and experienced by the women on the REDress organizing committee. As Morningstar says:

We've all been there. We've all walked the streets and had somebody chirp us and make us feel uncomfortable, unworthy or vulnerable, and you just kind of shake your head and think, "what the fuck". But there are women out there where that gets told to them and that's the only attention that they will ever see, so they're vulnerable to that. And sometimes they'll allow it, or think that it's okay... because they have been in situations where it hasn't been taught to be not okay.

The women in the REDress organizing committee have experienced racism throughout their lives. They have been subjected to the devised colonial narratives created about Aboriginal women. These narratives were constructed in order to delegitimize the positions of Aboriginal women in their communities by defining them as incapable. This involved taking away traditional roles that were deeply instilled with meaning, such as those held "in government and in spiritual ceremonies" (AJIC 1999). Instead, Indigenous women were subjected to notions of female inferiority, thereby ceasing to exist in their independent right, and becoming dependant on their husbands. Being "reduced to a state or powerlessness and vulnerability" undermined the fabric of traditional Indigenous communities (AJIC 1999).

The REDress project can be viewed as a tool through which dehumanizing narratives about Aboriginal women can be resisted by first recognizing their presence and their absence (Morningstar). The aspect of invisibility, evidenced in failed police protection and government inaction, can be challenged when Indigenous women are no longer silent (RCMP 2014). The REDress project is a method of resisting this imposed silence.

Miss Cremo talks about the way in which history must be decolonized; the system has to start teaching more than a one-sided story. The opinions and knowledge of Indigenous peoples 
have been deliberately excluded from what is considered Canadian history, thereby perpetuating and legitimizing the power of those who distribute information. Holding the REDress project in an academic institution opens up the dialogue about missing and murdered Aboriginal women, and allows people to think critically about the reasons why Aboriginal peoples are in their current situations. When speaking about the outcome of this project, Miss Cremo says that she hopes the REDress project contributes to the larger issues at hand:

We're not going to be oppressed anymore and the institution is going to allow education, Aboriginal education, to be heard, because it's not...just first nation's history or 'it's just our truth', no, it's everyone's truth, it's everyone's history and we have to make sure that we bring that out in our classrooms.

Having the red dresses on display in an academic institution both indirectly and directly challenges the one-sided story of history that is commonly taught at universities (TRC 2012). The direct effect of the dresses is that they make a bold statement, grabbing the attention of the viewers (See Figure 5). Indirectly, the red dresses represent larger systemic issues that must be acknowledged in order to move forward.

To bring attention to the current issues that are a result of history is a call for people to pay more attention to what has happened, and to question why Aboriginal peoples are in the position they are today. Jasmine adds that "this is what StFX needs, this diversity". To raise awareness about the crisis of missing and murdered Aboriginal women is to engage with the reality that many peoples face, and to acknowledge the hurt that history has caused. Moreover, the promotion of awareness about missing and murdered Aboriginal women can foster an environment where people begin to talk about issues, as Jasmine says, "it doesn't take a special person to realize that something is wrong, to see that there is an issue". In promoting awareness, the REDress project provides a fundamental perspective in understanding the neglected facets of our shared history.
Although the REDress project raises awareness about the present circumstances of Aboriginal communities in regard to the crisis of missing and murdered Aboriginal women, the project itself does not directly address the underlying systemic issues that are inherently racist. The project calls attention to the present circumstances of missing and murdered Aboriginal women, but does not offer any context into why this situation is occurring. The problems presented by the ERC's practices of event-application and risk-mitigation demonstrate how challenging it can be to create politically engaged statements on campus. Jasmine elaborates:

I definitely like the campaign because I feel like it brings a lot of awareness, but I feel like it brings awareness to the women that are missing, but not to an extent the sort of systemic problems that lie behind those reasons... [The red dresses] make it look flashy and it makes people think about things in sort of a critical way, but it doesn't give a full image.

While the project can encourage people to think in a more critical manner about the issue of missing and murdered Aboriginal women, the inclusion of increased contextual evidence could provide a more holistic understanding of the systemic racism Aboriginal peoples must endure. This may include a more interactive exhibit, wherein more information is given about the issue. The crisis of missing and murdered Aboriginal women is only one issue that Aboriginal people are faced within a society that does not equate their personhood with humanity. By calling attention to the crisis itself, people in the community can gain a better understanding of the current situation that Aboriginal peoples are forced to face. However, the REDress organizing committee felt as though there needed to be more of an impact in order to actually become a catalyst for change. As Jasmine illustrates, "it's bringing awareness, I think it's nice, but what's next? This awareness has been brought but how do we eliminate this issue, how do we move forward together?" 
Beyond Invisibility: Honouring our Sisters It is the dresses that mark the absence of the women who have gone missing or been murdered. Their absence is felt, and their presence is missed. The way in which the dresses move in the wind, it is almost as if there are spirits that inhabit them. They move, and they feel alive. One participant described the dresses as looking like "ghosts", which in a way, they are meant to. However, even if their bodies are gone, their restless spirits remain, and I think that is something that the dresses portray, "their spirits are broken, but it's not that it can't be fixed" (Morningstar). To Morningstar, the dresses go beyond respecting Aboriginal women. Instead, they honour the lives of missing and murdered Aboriginal women; "when you honour someone, that's everything. Their mind, their body, their spirit, like them. That individual... it takes courage and self-love to be able to honour people".

When addressing the functionality of the exhibit, Miss Cremo talks about the way in which the project works to create a more definitive pathway for the next stages of action to occur. Importantly, she addresses the need for Aboriginal women to be self-determining in the process:

I think that what the REDress project is, [is] that it's a stepping stone. And I think that if we didn't have that, where else would we go? We wouldn't have these discussions; we wouldn't have these questions to do more. So I think that it is up to individuals, as independent women, coming together as sisters, being united, and we have to make sure that we keep pushing forward because we see those [dresses] and we understand those, but it's our duty to make sure that its not silent.

The awareness generated through the project creates avenues for empowerment. The resiliency, strength and determination of Indigenous women are factors that are evident and at the forefront of the platform. As such, women are enabled to hold each other accountable, to set the record straight and to change the perceptions of people around them with regard to history and culture. When the lives of Aboriginal women are honoured, it reinforces the fact that they matter.

\section{Connecting to Culture}

It is important to consider the way in which the REDress project establishes a platform to generate positive understandings of identity for Indigenous women. Morningstar mentions that "everything comes back to identity. And I feel like your identity is twisted to how society should make you want to feel". The red dresses serve as a symbol to contrast the invisibility of Aboriginal women and reassert an identity of value, as opposed to previous notions of indifference. The project's main goal is to break this silence and call attention to the issue. This did occur within the StFX and Antigonish community, when local newspapers and radio stations were investigating the issue and asking more as a result of the REDress project.

The perception of the organization committee is that the project does not incorporate Aboriginal culture into the representation of Aboriginal woman. Though the humanity of the woman may be recognized as being in the dresses themselves, the individual realities and situations of Aboriginal women who have gone missing and been murdered is not revealed. The collective identity of Aboriginal women allows them a personal connection with the REDress exhibit, however, the organizing committee was unsure that it would be able to evoke the same emotion for people who had not experienced the same degree of loss and violence in their lives. People may note that a life was lost, but they may not see the impact that such losses have on communities and societies on a larger scale. Jasmine describes her opinion:

I feel like the campaign is really nice, but does it reflect our culture? No. I don't feel like it does. Does it reflect who we are as individuals? No. Or who these women are? No. It's nice because it represents their missing presence and their spirit... I feel like I can understand that, because this is me. My people, my sisters, my mother, my aunties and my cousins, and I see those important women in those dresses, but for people who don't have that connection they 
don't understand that. They don't understand the culture, they don't understand the history, they don't understand what sort of situation that brought these women to no longer be with us. And I feel like that is what is missing.

Jasmine also talks about how important it is that she is able to connect with her culture and allow it to build her back up.

I'm glad that I can take a step back and sort of take myself out of the picture and look at it, but a lot of our people don't know how to do that, or they ask themselves why are they in this predicament and not realizing that there is a systemic reason as to why you are in your predicament. And instead of blaming individuals, you got to blame the system. That's what's failing.

The ability to separate herself from the imposed identity of the state, one which is invisible or unimportant, is a critical element to her everyday success. Moreover, the cycle of blame referred to denotes the idea that Indigenous peoples have perpetuated their own self-inflicted misfortunes. It is a method used to evade responsibility of the state's obligation to maintain the welfare of its citizens. Recognizing that the government has caused, and continues to cause, many of the issues Indigenous peoples face today (such as alcohol abuse, drug addiction and high rates of suicide) allows Jasmine to disassociate herself with the cycles of blame imposed onto her. Instead, to look at the system and understand the ways in which it is failing gives her the power to work towards changing the current systemic barriers and racist attitudes that Aboriginal peoples face in society.

\section{The Power of Knowing}

The act of coming forward and sharing our stories is important. To shed light on the current issues is to also begin processes of healing. When Aboriginal women feel the effects of healing, there is an opportunity for empowerment. Jasmine reflects on her own story:
Being able to shine light on people's story is important because it empowers other people to step forward and to recognize what's happening isn't right, and that you shouldn't be silent and if that justice system doesn't work, I have my sisters; my supports who allow me to stand tall and to be proud, knowing I can step forward and be truthful.

Calling attention to the harms that have occurred against, and that continue to harm Aboriginal women, is important because acknowledging the past is the first step towards creating a better future. Being able to relate through stories and experiences is something that the REDress project encourages through the statement that sexual violence is prevalent in the lives of Aboriginal women. It may serve as a reminder that one is not alone in their "walk" and that there is hope for the future.

\section{Considering the Other Side of History}

The REDress project does not reinstate the humanity of these women, but Miss Cremo states that in the dresses, "I see hope, and I see that our women are going to be okay and regain our power and make sure that we're heard". The loss of power and strength of Aboriginal women through decades of colonization and intergenerational trauma is one of the first things that needs to be regained before any course of action is taken. Jasmine explains why understanding history is so important:

I feel like when people think that they don't feel the history behind it and they don't understand that there has been so much violence and oppression and just, I always struggle to use the word genocide, but that's what I believe has happened to our people. And it's not just women, but men and children and elders. Since the day of colonization, since the day they discovered the New World, it's just like, that messes people up. Can you imagine being a man, and in our society you're a warrior, you're a protector of your people, and have 
these intruders come in and rape and kill and slaughter your family, our elders, your whole systems, and you can't do anything about it? Imagine what kind of psychological effects that has on somebody. And then you put that into reproduction. Those traits automatically get passed down to your children. You know what I mean? I just feel like people don't really understand that there are reasons why people do the things they do.

Without taking history into account, the present situation facing Aboriginal peoples, notably the high rates of missing and murdered Aboriginal women, cannot be completely understood. The intergenerational trauma that reverberates through some Aboriginal communities, a result of colonization, is often overlooked. This cultural genocide has been sanitized throughout history with the passage of time, but needs to be exposed for what it really is. The REDress project demonstrates the current crisis of missing and murdered Aboriginal women, a potent illustration of the effect of bureaucratic and legislative disregard, that is occurring throughout this country.

\section{The REDress Project: Encouraging \\ Reconciliation}

There are two dimensions of reconciliation that the REDress project encouraged on the StFX University campus. Firstly, at the public level, evidence by the increase in awareness of the crisis of missing and murdered Aboriginal women within the campus and community. Secondly, at the interpersonal level, wherein myself and other members of the committee created "lifelong friendships" (Morningstar).

\section{Large Scale Reconciliation}

The REDress project has potential to open doors to further education about Indigenous culture and incorporate their ways of being into the educational system. One of the biggest factors of reconciliation is that it requires an honest relationship between Aboriginal and non-Aboriginal populations. Miss Cremo says that what is necessary to begin the process of reconciliation is "for us to work together and build a stronger community, we have to work together. We don't have to assimilate, but have people who are able to push us in the right directions". She indicates that there needs to be more support for Aboriginal students within the university system, which starts with the recognition that they have been systemically disadvantaged for years. In this case, it is not necessarily about giving everyone the same resources so they can access education, it is about creating bonds of solidarity within the system so that Aboriginal students can feel their culture is represented in the institution (TRC 2012).

The REDress project exemplifies the alternative avenues of learning that can be used by the institution, and furthermore, should be encouraged. This type of learning, when taken into the hands of Aboriginal women themselves, demonstrates not only their resilience and strength, but their capacity to carry out education processes that encourage reconciliation between Aboriginal and nonAboriginal students in government funded institutions. It is also evident that the exhibit garnered enough respect from the students and faculty at the university to support its continued exhibition. I think that this example shows the willingness of the community to help and to engage in activities that are representative of reconciliation.

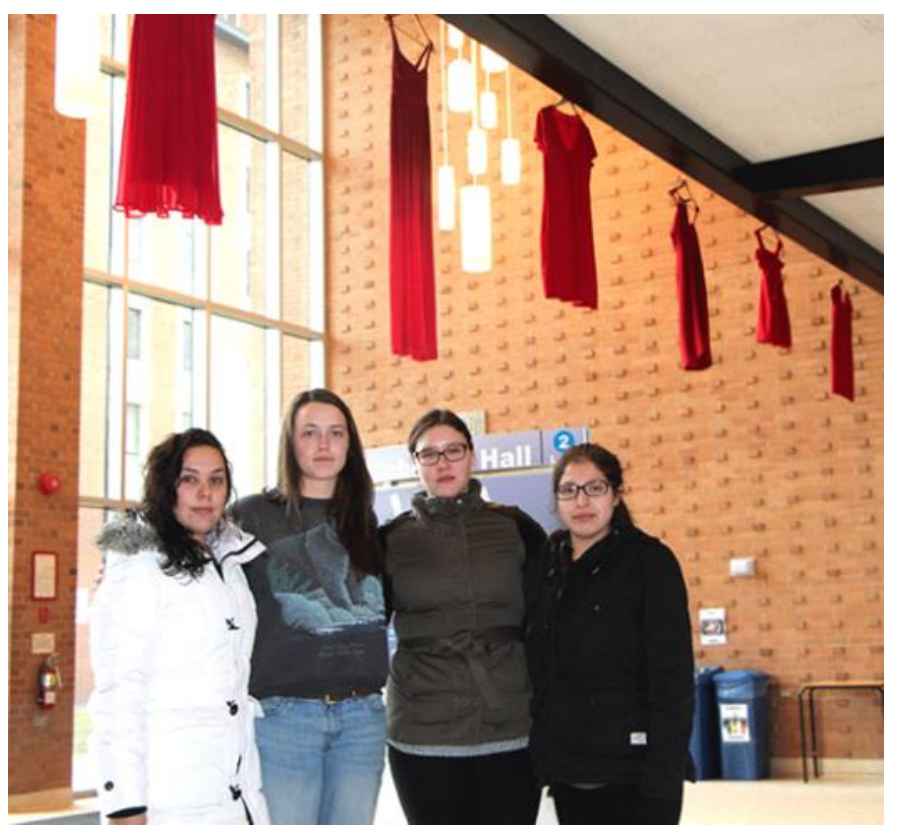

Figure 7: (Left to right) Morningstar, Natalie, Jasmine and Miss Cremo. This picture was featured in the Antigonish Casket, the local newspaper, 2016

(Source: Antigonish Casket) 


\section{Interpersonal Reconciliation}

The women in the REDress organizing committee felt that the project reflected one of the most fundamental elements necessary for reconciliation to take place, which is recognition: recognition of the past, and the way in which it has influenced the present. In this way, the REDress project and the steps involved in the organization of the exhibit create a microcosm of the larger social situation. With respect towards more largescale efforts of reconciliation, Morningstar reflects on the way in which the REDress project embodies the most important aspects of the treaties:

Look at this [points to dresses], we have a lifelong friendship here that we developed just from having Natalie reach out. And when we talk about making those things personal, that's what it is, its creating those friendships. Those treaties were created for peace and friendship and this is us living it out. And that's the take home from this, for the community and the institution and the faculty and the students to realize that it's a partnership (See Figure 6).

Efforts of reconciliation through this process begin from the ground up. The relationships formed throughout the REDress project can be viewed as an act of reconciliation in part because of the PAR process. Largescale reconciliation, such as that between Indigenous and other Canadian systems of governance, must first rectify relationships on the individual level.

Importantly, PAR allowed for there to be transparency in the research process, which instilled meaningfulness in the relationships that were developed throughout the project. These are qualities that should continue to inform community and grassroots level projects that involve Aboriginal and non-Aboriginal populations, so as to embody those elements that Morningstar speaks to truth and reconciliation.
With regard to the Truth and Reconciliation Commission, and the efforts that have taken place in Canada to gain momentum with regard to reconciliation, Jasmine states that:

When we talk about truth and
reconciliation, that first word is
truth, and I feel like this... it just
shows so much truthfulness. That's
the first step in recognizing and
understanding that this is an issue,
that this is a problem, now it's like
how do we work together to push
forward and to do better. That's
definitely what I hope that people
get from that.

This comment demonstrates Jasmine's view that there needs to be better recognition of the situation that Aboriginal people in Canada face. The REDress project should be viewed as a way to raise awareness about the issue, especially among populations who perhaps do not have direct exposure to it. This is important because without recognition of the wrongs done there will not be space for movement forward.

\section{Encouraging Empowerment}

By moving Aboriginal peoples away from the periphery and toward the center of knowing, their voices are accorded importance and value. Solidarity comes from the shared experiences that a common identity is based upon, and is something that Indigenous females today may not necessarily have access to as a consequence of colonialism. In line with the Indigenous feminist perspective, women have the ability to empower each other when they come together. The women involved in the REDress organizing committee demonstrated the sense of unity that arose between us as a result of our work together and support for each other along the way.

Our friendship is based on principles of honesty and respect, which are two elements that have been absent in the relationships that characterize many Aboriginal and nonAboriginal relationships. PAR allowed for a decolonized approach to research, wherein a transparent process guided our activity. It encouraged a space where hierarchy between researcher and participants was mitigated by 
the larger process of action that required cooperation, trust, and collaboration. The organization of the REDress committee was largely a product of equal involvement by all participants, including myself.

\section{Moving Forward}

As the late Patricia Monture-Angus, Mohawk lawyer, activist and educator has demonstrated (1995), violence is equally as effective when manifested in silence. The REDress project is important because it is a way through which silence can be broken. When a population is silenced by the force of domination, they also may be silenced within themselves. It may not be what we cannot say to each other, but rather what we cannot say to ourselves that causes the most pain (Sider 2014: 19). By bringing attention to the problem, potential pathways towards healing can be recognized.

That the red dresses are emblematic of blood, the life-force that runs through our veins, and more specifically bloodshed and blood that has been lost, points to the fact that the crisis of missing and murdered Aboriginal women is an ongoing struggle. As Sider (2014) states, "struggle itself not only dignifies but heals" (20). Raising awareness about the situation requires breaking the silence that Aboriginal women have been subjected to. The REDress project becomes a symbol of empowerment, then, because it breaks the silence that has characterized much of the engagement and relationship between the Indigenous and non-Indigenous peoples.

\section{Community-Based Collaboration and \\ Reconciliation}

Instead of continuing the cycles of blame that frame Aboriginal peoples as the source of problems that are actually caused by societal oppression, collaborative projects recognize that social and political structures constrain Aboriginal populations. As such, the combination of ideas can strengthen and create new systems that are "directed at changing institutions that deal with indigenous peoples, and not at changing indigenous peoples to fit the structures" (Smith 2012: 148). Institutions are key in the dissemination of knowledge within society and have largely contributed to the continuation of colonization in present day (Smith 2012). The power embedded within the "prestige" of academia naturalizes the discourses and narratives that are provided by education and government institutions and the information being produced is therefore taken as "fact" and "provide ad hoc justification for the maintenance of inequalities and the continued oppression" of Aboriginal peoples (Smith 2012: 188). To disrupt these traditional practices and offer an Indigenous alternative by using PAR is thereby a strategy that aims to include Indigenous understandings within the dominant systems of society. Such inclusion within the system has the potential to allow Indigenous knowledge to be accepted on a wider societal scale.

In understanding the way that the crisis affects not only Aboriginal peoples but the wider community and the country as a whole, by means of addressing safety concerns and recognizing racism, non-Aboriginal peoples can begin to understand the importance of raising awareness and creating allies on large scale. As a non-Aboriginal student, my involvement in the organizational efforts of the REDress project exemplifies the kind of connections used to raise awareness about a critical Indigenous issue.

The REDress project, as a grassroots initiative, is described by Miss Cremo as a "stepping stone". The exhibit serves as a way to raise awareness about the crisis of missing and murdered Aboriginal women in the community but does not necessarily depict the larger systemic issues that the crisis is rooted in. However, the nature of grassroots activism allows for relationships that are not structured by the larger system to be established. Such efforts will serve to structure a fairer and more equitable system in the future because they are based on more sustainable and promising principles. Grassroots initiatives are important because they encourage more equal representation of Indigenous and nonIndigenous peoples without the constraints of systemic racism limiting interaction. The REDress project is a materialized effort that compliments this academic research in creating change. 


\section{Conclusion}

The REDress project opposes the ascribed invisibility of Indigenous women in Canadian society. The hanging of red dresses in public spaces serves as a political statement of collective resistance to the inactivity, ignorance and avoidance by systems of government that have long perpetuated the problem. Honouring the lives of women who have gone missing or been murdered is also an integral part of recognition, which then enables efforts of healing. The resulting awareness that is created through the project is dependent on the way in which it is presented, which makes using a PAR approach highly effective. The combined efforts of both Indigenous and non-Indigenous students were carried out on principles of equality and transparency, wherein both parts had the same opportunity to contribute and lead. As a community-based initiative, the REDress project created a space for the beginning of reconciliation, cultivating dialogue and producing meaningful action oriented toward a successful and effective awareness campaign. 


\section{References}

Aboriginal Justice Implementation Commission. 1999. Report of the Aboriginal Justice Inquiry of Manitoba. Manitoba: Aboriginal Justice Implementation Commission.

Archuleta, Elizabeth. 2006. "I Give You Back: Indigenous Women Writing to Survive." Studies in American Indian Literatures 18 (4): 88-114. doi: 10.1353/ail.2007.0000.

Black, Jamie. 2014. "The REDress Project." Accessed November 22, 2015. http://www.theredressproject.org.

Cannon, Martin and Lina Sunseri. 2011. Racism, Colonialism, and Indigeneity in Canada. Toronto: Oxford University Press.

Couture-Grondin, Élise and Cheryl Suzak. 2013. “The Becoming of Justice. Indigenous Women's Writing in Pre-Truth and Reconciliation Period." Transitional Justice Review. 1 (2): 97-152.

Cunningham, Myrna. 2006. "Indigenous Women's Visions of an Inclusive Feminism." Development 49 (1): 55-59. doi:10.1057/ palgrave.development.1100227. https://search.proquest.com/ docview/216912832.

Geertz, Clifford. 1973. The Interpretation of Cultures; Selected Essays. New York: Basic Books.

Georges Erasmus, and René Dussault. 1996. RCAP (Report of the Royal Commission on Aboriginal Peoples). Ottawa: The Commission.

Maracle, Lee. 1996. I Am Woman: A Native Perspective on Sociology and Feminism. 2. ed. Vancouver: Press Gang.

Marrouat. "Exhibition Review: 'REDress Project'." Accessed November 20, 2015. http://www.examiner.com/review/exhibition-reviewredress-project.

Monture-Angus, Patricia. 1995. Thunder in My Soul: A Mohawk Woman Speaks. Halifax: Fernwood Publishing.

NWAC (Native Women's Association of Canada). 2010. “What Their Stories Tell Us: Research Findings from the Sisters In Spirit Initiative." Ottawa: Native Women's Association of Canada.

NWAC (Native Women's Association of Canada). 2015. "Fact Sheet: Missing and Murdered Aboriginal Women and Girls." Ottawa: Native Women's Association of Canada. 
Oppal, Wally. 2012. "Forsaken: The Report of the Missing Women Commission of Inquiry - Volume IV: The Commission's Process." Report, Government of British Columbia.

Razack, Sherene. 2015. Dying From Improvement. Toronto: University of Toronto Press.

Royal Canadian Mounted Police. 2014. "Missing and Murdered Aboriginal Women: A National Operational Overview." Report, RCMP.

Sider, Gerald M. 2014. Skin for Skin: Death and Life for Inuit and Innu. Durham: Duke University Press.

Smith, Linda Tuhiwai. 2012. Decolonizing Methodologies. 2nd ed. Dunedin: Otago University Press.

Squires, Dave. 2015. "Vandalism of REDress Art Project seen as Further Violation of Missing and Murdered Aboriginal Women." Global News, October 30, 2015. https://globalnews.ca/ news/2309641/vandalism-of-redress-art-project-seen-as-furtherviolation-of-missing-and-murdered-aboriginal-women/.

Suzak, Cheryl, Huhndorf Shari, M., Perreault, Jeanne, and Jean Barman. 2010. Indigenous Woman and Feminism: Politics, Activism, Culture. Vancouver: UBC Press.

Truth and Reconciliation Commission of Canada. 2012. Truth and Reconciliation Commission of Canada interim report. Winnipeg: Truth and Reconciliation Commission of Canada. 